\title{
REVIEW
}

\section{Involvement of the TGF- $\beta$ superfamily signalling pathway in hereditary haemorrhagic telangiectasia}

\author{
Carmelo Bernabéu, Francisco Javier Blanco, Carmen Langa, Eva María Garrido-Martin, \\ Luisa María Botella
}

Centro de Investigaciones Biológicas, Consejo Superior de Investigaciones Científicas (CSIC) and CIBER de Enfermedades Raras (CIBERER), 28040 Madrid, Spain

Received $23^{\text {rd }}$ February 2010.

Revised $29^{\text {th }}$ April 2010.

Published online $13^{\text {th }}$ May 2010.

\begin{abstract}
Summary
Hereditary haemorrhagic telangiectasia (HHT) is a vascular hereditary autosomic dominant disease associated with epistaxis, telangiectases, gastrointestinal haemorrhages and arteriovenous malformations in lung, liver and brain. It affects $1-2$ in 10,000 people. There are at least three different genes mutated in HHT, ENG, $A C V R L 1$ and MADH4 that encode endoglin, activin receptor-like kinase (ALK1) and Smad4 proteins, respectively. These proteins are involved in the transforming growth factor (TGF)- $\beta$ superfamily signalling pathway of vascular endothelial cells. Mutations in ENG (HHT1) and ACVRL1 (HHT2) account for more than $90 \%$ of all HHT mutations. In this article, we review the underlying molecular and cellular bases and the therapeutic approaches that have been addressed in our laboratory in recent years.
\end{abstract}

Key words: transforming growth factor; endothelial cells; hereditary haemorrhagic telangiectasia; endoglin; ALK1; Smad; anti-fibrinolytic agents; estrogens

\section{HEREDITARY HAEMORRHAGIC \\ TELANGIECTASIA: CLINICAL MANIFESTATIONS AND GENES INVOLVED}

Hereditary haemorrhagic telangiectasia (HHT) or Rendu-Osler-Weber syndrome is a vascular hereditary autosomic dominant disease associated with epistaxis, telangiectases, gastrointestinal haemorrhages and arteriovenous malformations in

\begin{tabular}{ll}
\hline$\square \quad$ Carmelo Bernabéu, Centro de \\
Investigaciones Biológicas (CSIC), Ramiro \\
de Maeztu 9, Madrid 28040, Spain \\
bernabeu.c@cib.csic.es \\
量 $\quad+34-91-8373112$ \\
司 $\quad+34-91-5360432$ \\
\hline
\end{tabular}

lung, liver and brain. Prevalence is around 1-2 in 10,000 according to recent reviews (Abdalla and Letarte 2006, Govani and Shovlin 2009). The disease is included in the Online Mendelian Inheritance in Man (OMIM; \#187300; \#600376; \#175050). The diagnosis is based on clinical criteria, known as the Curaçao criteria (Shovlin et al. 2000). A person is considered as an HHT patient if she/he has, at least 3 out of the following 4 criteria: (i) spontaneous and recurrent epistaxis; (ii) multiple telangiectases at characteristic locations (lips, oral cavity, fingers, nose); (iii) visceral lesions (gastrointestinal telangiectases, pulmonary, hepatic, cerebral or spinal arteriovenous malformations-AVMs); or (iv) a first degree relative with HHT. The penetrance of the disease increases with age and at 45 years, is about 90\% (Plauchu et al. 1989). Since HHT patients may have lung and brain arteriovenous malformations before the onset of epistaxis and telangiectasia, the 
establishment of an early molecular diagnosis is necessary. These malformations may give rise to complications, such as brain ictus, brain infarction, brain abscesses, massive haemoptysis and paralysis. International guidelines for the diagnosis and management of HHT have been recently reported (Faughnan et al. 2010).

Two loci are involved by mutation in more than $90 \%$ of HHT cases. The first gene identified was ENDOGLIN (ENG) that maps to chromosome 9 (Fernández-Ruiz et al. 1993, McAllister et al. 1994), representing between $39-59 \%$ of the total HHT population. Next, ACVRL1 (activin receptor like kinase 1, also known as $A L K 1$ ) that maps to chromosome 12 was described (Johnson et al. 1996) as being involved in $25-57 \%$ of HHT cases. Mutations in $E N G$ and $A C V R L 1$ give rise to HHT1 and HHT2 types, respectively. Up to date more than 700 different mutations have been described in $E N G$ and $A L K 1$. In around $2 \%$ of the total HHT population, the origin of the disease is a mutation in the MADH4 gene leading to the combined syndrome of Juvenile Polyposis (JP) and HHT (JPHT), although an overlapping spectra of MADH4 mutations in JP and JPHT has been found (Gallione et al. 2010). Two additional loci were described on chromosome 5 and chromosome 7, whose genes are still unidentified (Govani and Shovlin 2009). Haploinsufficiency is accepted as the cause of HHT1 and HHT2 pathogenicity (Abdalla et al. 2006).

\section{REGULATED EXPRESSION OF HHT GENES}

Endoglin and ALK1 are expressed in endothelial cells (ECs), which are the primary cell target in HHT. Endoglin is expressed at low levels in resting ECs, but at high levels in endothelial proliferating cells at sites of active angiogenesis and during embryogenesis (Bernabéu et al. 2009). Other cell types that express endoglin at their surface are macrophages, erythroid precursors in bone marrow, syncytiotrophoblasts and several cell types closely related to the cardiovascular system such as smooth muscle cells of atherosclerotic plaques and cardiac fibroblasts (Bernabéu et al. 2007). The human $E N G$ promoter does not contain TATA or CAAT transcription initiation boxes but has GC-rich regions and consensus sites for Sp1, Ets, AP-2, NFкB, GATA and Smad binding elements (SBE) (Rius et al., 1998). The basal activity of ENG transcription involves the proximal Sp1 motifs and an Ets site at -68 (Rius et al. 1998, Botella et al. 2001). Whereas the restricted expression to endothelium requires the presence of enhancers that bind Ets family members, a negative regulation involves the presence of repressors that recruit Pu.1 and GATA-2 to inhibit $E N G$ expression in blood stem/progenitors (Pimanda et al. 2008).

Upregulated expression of endoglin was found in inflamed or infected tissues, healing wounds, psoriatic skin, synovial arthritis, upon vascular injury and in tumoural vessels (Bernabéu et al. 2007, Fonsatti et al. 2010). There is a variety of stimuli responsible for the increased endoglin expression in activated vessels, including hypoxia, vascular injury and related cytokines. Indeed, endoglin expression is upregulated after ischemia in the heart, kidney and hind-limbs, as well as upon arterial injury (Botella et al. 2002, Bernabéu et al 2007). Under hypoxic conditions, the hypoxia inducible factor-1 (HIF-1) complex binds a functional consensus hypoxia responsive element (HRE) in the $E N G$ gene promoter (Sánchez-Elsner et al. 2002). TGF- $\beta$ signalling, via Smad transcription factors, also potently stimulates endoglin expression (Rius et al. 1998, Botella et al. 2001). Whereas hypoxia alone moderately stimulates endoglin transcription, the addition of TGF- $\beta 1$ under hypoxic conditions results in a transcriptional cooperation between both signalling pathways, leading to a marked stimulation of endoglin expression. This synergic stimulation involves the formation of a transcriptional multicomplex containing Smad3/Smad4, Sp1, and HIF-1 (Sánchez-Elsner et al. 2002). Upon vascular injury, a transcriptional activation of endoglin mediated by the cooperative interaction between $\mathrm{Sp} 1$ and KLF6 transcription factors has been reported (Botella et al. 2002). Endoglin expression is also upregulated by synthetic agonists of the liver X receptor alpha, which binds to an LXR response element on the ENG promoter, suggesting the in vivo involvement of oxysterols, known as potent LXR activators (Henry-Berger et al. 2008). By contrast, tumour necrosis factor-alpha (TNF- $\alpha$ ) decreases endoglin protein levels in ECs (Bernabéu et al. 2007).

ALK1 expression has been reported not only in highly vascularized tissues including lung, placenta, and heart, but also at specific sites of epithelial-mesenchymal interactions, and in other cell types such as monocytes, microglia, skin fibroblasts, stellate hepatic cells, chondrocytes, neural crest stem cells and more recently myoblasts (Bernabéu et al. 2007, Velasco et al. 2008). Nonetheless, most studies to date suggest that its major roles are related to the endothelial specific expression pattern. ALK1 is involved in angiogenesis and a regulatory region of ACVRL1 gene is sufficient for endothelial expression in arteries feeding ischemic tissues ( $\mathrm{Li}$ et al. 2009). The characterization of the ACVRL1 promoter and the 
study of its transcriptional regulation remain largely unknown. As in the case of ENG, the ACVRL1 proximal promoter does not contain TATA or CAAT boxes, but has multiple GC-rich regions that recruit Sp1 to regulate basal transcription. ALK1 presents several transcriptional start sites and $\mathrm{Sp} 1$ is a key factor involved in its transcriptional regulation. Moreover, the methylation status of $\mathrm{CpG}$ islands markedly modulates the activity of the ALK1 promoter region.

\section{STRUCTURE OF ENDOGLIN AND ALK1}

Both endoglin and ALK1 are type I membrane proteins. Endoglin is expressed as a $180-\mathrm{kDa}$ disulfide-linked homodimer (Gougos and Letarte 1990). It contains a large extracellular domain of 561 amino acids, highly glycosylated mainly in asparagine residues. Structurally, endoglin belongs to the Zona Pellucida (ZP) family of proteins that share a ZP domain of $\sim 260$ amino acid residues at their extracellular region (Jovine et al. 2005, Llorca et al. 2007). The three-dimensional structure of the extracellular domain of endoglin at $25 \AA$ resolution, using single-particle electron microscopy has been elucidated for the first time in our group (EMDB Entry: EMD-1559) (Llorca et al. 2007). Endoglin is arranged as a dome made of antiparallel orientated monomers enclosing a cavity at one end. Each subunit comprises three well-defined regions, two of them corresponding to the ZP domain. The third region does not show any significant homology to other protein family/domain and thereby has been named the "orphan" domain. A transmembrane region, spanning 25 hydrophobic residues, acts as a linker between the ectodomain and the cytosolic region. Two different alternatively spliced isoforms, the predominant long (L)-endoglin and the minor short (S)-endoglin, are expressed in human and mouse tissues (Gougos and Letarte 1990, Bellon et al. 2003, Pérez-Gómez et al. 2005). In humans, S-endoglin and L-endoglin proteins vary from each other in their cytoplasmic tails that contain 14 and 47 amino acids, respectively, with a sequence of only 7 residues being specific for S-endoglin. Both endoglin isoforms are constitutively phosphorylated and can be targeted by serine/threonine kinases, including the TGF- $\beta$ type I (ALK1, ALK2 and ALK5) and II receptors (Guerrero-Esteo et al. 2002, Bernabéu et al. 2007). L-endoglin cytoplasmic domain contains a consensus PDZ binding motif (SerSerMetAla) at the carboxyl terminus that mediates endoglin interaction with several PDZ domain-containing proteins and endoglin phosphorylation of distal threonine residues (Bernabéu et al. 2007, 2009).

ALK1 is a transmembrane protein of approximately $55 \mathrm{kDa}$ with an $\mathrm{N}$-glycosylated ectodomain of 97 amino acids carrying a cysteinerich small sequence which probably confers the appropriate structural conformation to capture the ligand. The ALK1 cytoplasmic region of 362 amino acids contains (i) a GS domain, a conserved 30 amino acids glycine/serine-rich sequence involved in the regulation of the receptor activation and (ii) a serine/threonine kinase domain. Phosphorylation of serine/threonine residues of ALK1 in the GS domain by the type II receptor (T $\beta$ RII) leads to a conformational change in ALK1 that allows phosphorylation of the downstream signalling molecules Smad1, Smad5 or Smad8 (Gordon and Blobe 2008, Goumans et al. 2009). Although there are no data about the three dimensional structure of ALK1, it is possible to build a theoretical model of its cytosolic domain using homology modelling techniques based on the crystal structure of the type I receptor ALK5 (PDB: 1IAS) (Fontalba et al. 2008). The ALK1 structure of the cytosolic domain contains the L45 loop, a small region that interacts with Smads, which confers the signalling specificity among different type I receptors. In addition, the cytosolic region of ALK1 contains a consensus motif between residues 399-406 for the interaction with the scaffolding domain of caveolin-1, a major protein component of caveolae (Santibanez et al. 2008). As shown in Fig. 1, most of ALK1 mutations in HHT2 patients involve the cytoplasmic domain, at variance with HHT1 where endoglin mutations map to the extracellular domain (Fontalba et al. 2008).

\section{FUNCTION OF PROTEINS ENCODED BY HHT GENES. THE TGF- $\beta$ PATHWAY}

The three identified genes mutated in HHT ( $A C V R L 1$, $E N G$ and $M A D H 4$ ) encode for proteins involved in the TGF- $\beta$ signalling pathway (Gordon and Blobe 2008, Goumans et al. 2009, Govani and Shovlin 2009). Thus, ALK1 is a type I serine/threonine kinase receptor, endoglin is an auxiliary co-receptor without catalytic activity and Smad4 is a transcription factor that mediates the TGF- $\beta$ signalling downstream of the type I receptors (Fig. 2). Endoglin forms a protein complex with the TGF- $\beta$ types I and II receptors and the ligand. Several members of the TGF- $\beta$ superfamily, including TGF- $\beta 1$, TGF- $\beta 3$, activin-A, BMP-2, BMP-7 and BMP-9 are able to bind endoglin and/or ALK1. This binding triggers the 


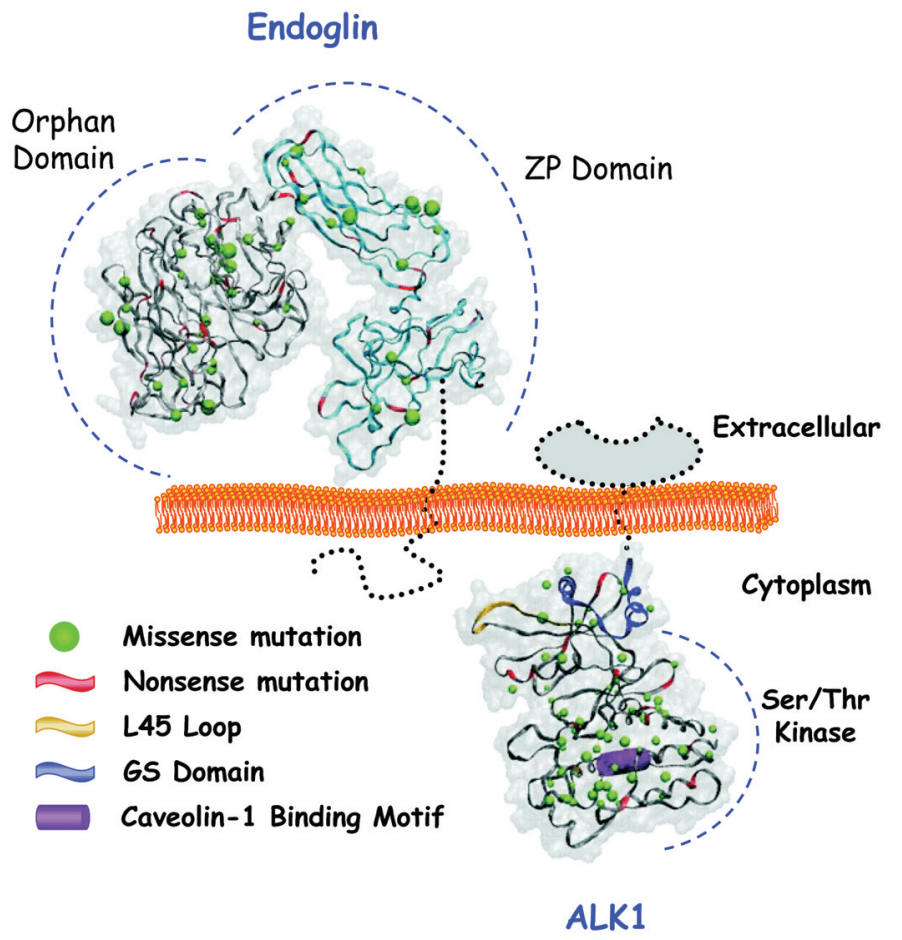

Fig. 1. Endoglin and ALK1 three dimensional structure and HHT mutations. The missense and nonsense mutations described for the extracellular part of endoglin and the intracellular part of ALK1 are shown as green spheres and red segments, respectively. The volume of the green spheres is exclusively related to the size of the mutated residue side chain. The L45 loop, the GS domain and the caveolin-1 binding motif of ALK1 are also indicated.

Smad-dependent downstream signalling (Guerrero-Esteo et al. 2002, Blanco et al. 2005, Gordon and Blobe 2008, David et al. 2009, Goumans et al. 2009). In ECs, endoglin modulates ligand binding and signalling by association with ALK1 and ALK5 (Guerrero-Esteo et al. 2002, Blanco et al. 2005, Santibanez et al. 2007, Velasco et al. 2008). Thus, endoglin inhibits the TGF- $\beta$ /ALK5/Smad3-mediated cellular responses such as the increased expression of the plasminogen activator inhibitor 1 (PAI-1). By contrast, endoglin promotes the ALK5/Smad2-mediated upregulation of endothelial nitric oxide synthase (eNOS) as well as the TGF- $\beta 1 / A L K 1-m e d i a t e d$ increase of Id1. Interestingly, endoglin inhibits the BMP-9/ALK1 signalling in ECs. Overall, endoglin appears to be a critical modulator of the balance between ALK1 and ALK5 signalling. This balance plays a crucial role during vascular remodelling and angiogenesis, although the underlying molecular mechanisms remain to be elucidated (Bernabéu et al. 2007, Lebrin and Mummery 2008, David et al. 2009, Goumans et al. 2009).
Different studies support the view that endoglin and ALK1 participate in a common signalling pathway that is critical for EC responses to TGF- $\beta$ family members (Bernabéu et al. 2007, 2009, Lebrin and Mummery 2008). This conclusion agrees with the fact that pathogenic mutations in $E N G$ or $A C V R L 1$ genes result in HHT and that ALK1 and endoglin null mice have similar vascular phenotypes (Abdalla and Letarte 2006). Recently, it has been shown that S-endoglin is up-regulated during senescence of ECs and exerts an antagonistic role to that described above for L-endoglin. S-endoglin is able to interact with both endothelial type I receptors, but showing much more affinity for ALK5 than for ALK1. Consequently, S-endoglin inhibits cellular proliferation and promotes the expression of the ALK5 target gene PAI-1, whereas the ALK1 target Id1 is repressed (Blanco et al. 2008, Velasco et al. 2008).

Endoglin is involved in the control of vascular tone. In fact, endoglin deficient mice $\left(\mathrm{Eng}^{+/-}\right)$show decreased levels of eNOS and elevated expression of cyclooxigenase-2 (COX-2), both of them key 


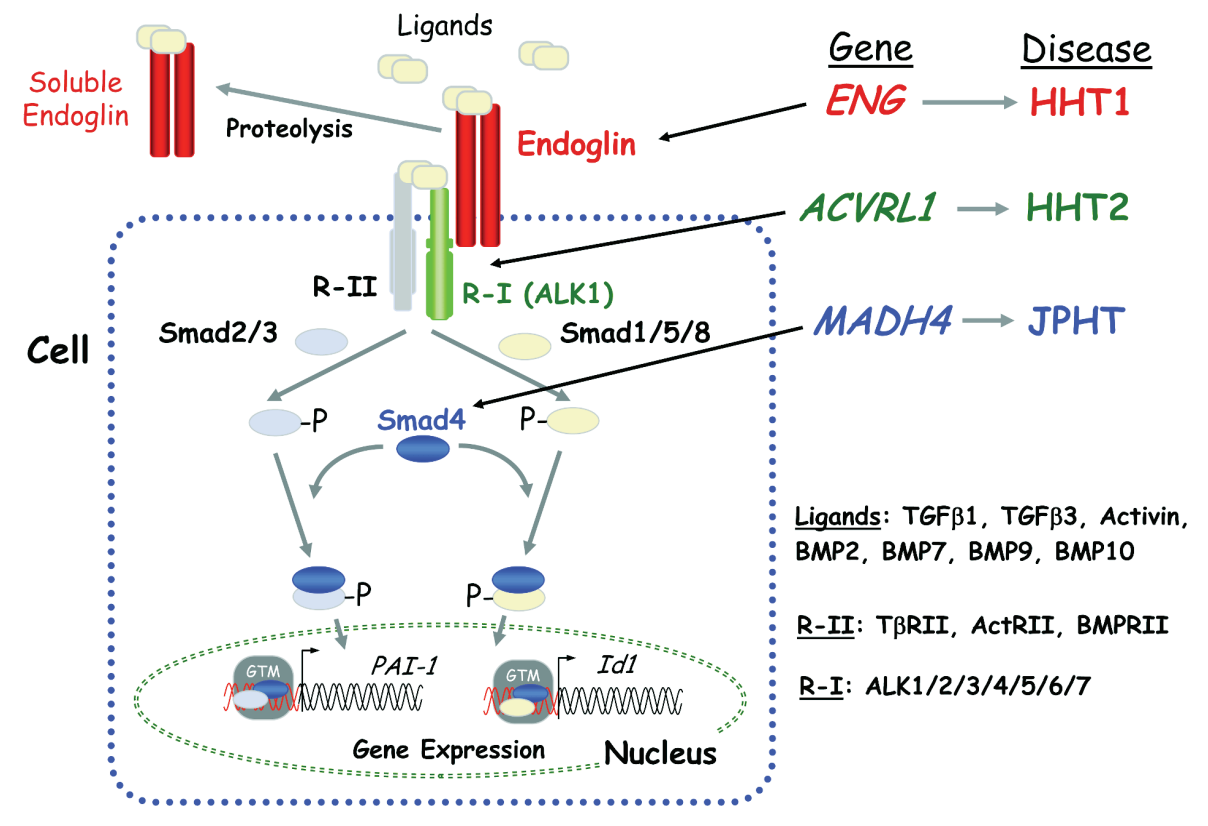

Fig. 2. HHT and the TGF- $\beta$ signalling pathway. Members of the TGF- $\beta$ family, which includes TGF- $\beta$ s, activins and BMPs, bind to specific type I (R-I) and type II (R-II) cell surface receptors that exhibit serine/threonine kinase activity. Endoglin is an auxiliary receptor that associates with ligand, R-I and R-II and modulates signaling via R-I and R-II. A soluble form of endoglin can be generated by juxtamembrane proteolysis of the membrane bound receptor that can sequester ligands and thereby modulating their binding to R-I/R-II. The combinatorial heterodimeric association between R-I and R-II determines the specificity of the ligand signalling. Upon ligand binding, the R-II transphosphorylates R-I, which subsequently propagates the signal by phosphorylating the receptor-regulated Smad (R-Smad; Smad1, 2, 3, 5, 8) family of proteins. Once phosphorylated, R-Smads form heteromeric complexes with a cooperating homologue named Co-Smad (Smad4), and translocate into the nucleus where they regulate the transcriptional activity of target genes (Gordon and Blobe 2008, Goumans et al. 2009). In ECs the R-I, ALK1 and ALK5 activate signalling pathways via Smad1, 5, 8 (ALK1) or Smad2, 3 (ALK5), respectively. Endoglin, ALK1 and Smad4 proteins are encoded by ENG, ACVRL1 and MADH4 genes, whose pathogenic mutations give rise to HHT1, HHT2 and JPHT, respectively. ActR, activin receptor; BMP, bone morphogenetic protein; BMPR, BMP receptor; GTM, general transcription machinery.

enzymes in the control of the vasodilator responses (Jerkic et al. 2006, Santibanez et al. 2007). It is noteworthy that transgenic mice expressing human S-endoglin $\left(S-E N G^{+}\right)$show a similar phenotype as $\mathrm{Eng}^{+/-}$mice, in agreement with the opposing effects of L-endoglin versus S-endoglin (Blanco et al. 2008).

Endoglin is also implicated in the cytoskeletal organization. The cytoplasmic tail of L-endoglin interacts with members of the LIM domain-containing family of proteins, including zyxin and ZRP-1 (zyxin-related protein-1) (Sanz-Rodriguez et al. 2004). Both proteins serve as docking sites for the assembly of multimeric protein complexes involved in regulating cytoskeleton, assembly and cell motility. Accordingly, blood outgrowth ECs from HHT patients show an abnormal shape compared to controls, exhibiting poor organization of the actin cytoskeleton due to disorganized actin fibers and depolymerization (Fernández-L et al. 2005). The organization of the capillary network during angiogenesis depends on the structure of ECs so that in the vasculature of HHT patients a disorganized cytoskeleton is prone to cell breaking with changes in shear stress and blood pressure. This might lead to vessel haemorrhages and eventual disappearance of the capillary network, as occurs in HHT.

Endoglin is emerging as a modulator of the TGF- $\beta$ response with important roles in cancer. It is highly expressed in the tumour-associated vascular endothelium with prognostic significance in selected neoplasias and is a vascular target for antiangiogenic cancer therapy (Bernabéu et al. 2009, Fonsatti et al. 2010). On the other hand, expression of endoglin in the tumour cells appears to play an important role in the progression of cancer, influencing cell proliferation, motility, invasiveness and 
tumorigenicity ( Pérez-Gómez et al. 2005, Wong et al. 2008, Bernabéu et al. 2009). In addition, in vitro and in vivo experiments in which endoglin expression is modulated have provided evidence that it acts as a tumour suppressor (Pérez-Gómez et al. 2007).

Increased levels of soluble endoglin have been detected in plasma, serum and urine from patients with different pathologies, including pre-eclampsia and cancer (Bernabéu et al. 2009). Circulating soluble endoglin is a reliable marker of preeclampsia and is associated with poor prognosis in cancer. Whereas it has been postulated a pathogenic role for soluble endoglin in preeclampsia due to its anti-angiogenic activity, the role of soluble endoglin in tumour progression remains to be established (Pérez-Gómez et al. 2007).

\section{HHT THERAPEUTIC APPROACHES. MOLECULAR MECHANISMS OF ACTION}

So far, there is no cure for HHT and there is a need to find an effective drug for its treatment. The pharmacological therapeutic strategies should be ideally aimed at: (i) improving the coagulation process or preventing the haemorrhagic condition; (ii) increasing the amount of endoglin or ALK1 on the EC surface, since the pathogenesis of the HHT condition is due to haplo-insufficiency; and (iii) decreasing angiogenesis, because an excess of abnormal angiogenesis has been reported in the HHT condition. There are five different types of pharmacological drugs used for the treatment of HHT bleeding (Table 1). In this review, we will focus on the clinical and molecular data regarding antifibrinolytic drugs and raloxifene, therapeutic agents used in our research group.

The basis for the efficiency of antifibrinolytic agents, epsilon aminocaproic and tranexamic acid (TA) relies on the inhibition of the fibrinolytic activity, by binding the active center of plasmin in the tissues that leads to clot stabilization. TA is a derivative of lysine (4-aminomethyl cyclohexanecarboxylic acid), which binds reversibly to plasminogen, avoiding fibrin degradation by plasmin (Manucci 1998). TA is indicated in severe bleedings with hyperfibrinolysis as it is the case of HHT, showing hyperfibrinolysis secondary to intravascular coagulation. Previous studies have described the use of TA for the treatment of HHT patients with an improvement in epistaxis and the associated anaemia (Sabba et al. 2001).

Since 2003, more than 250 patients from more than 100 different families have been screened by the
HHT unit in Sierrallana Hospital (Cantabria, Spain). A pilot series of oral TA treatment was conducted with a total of 14 patients which had severe epistaxis interfering with their quality of life. In all these cases side-effect risks of thrombosis were absent. All patients showed a decrease in the intensity and frequency of nose bleeds after the first week of treatment. None of them have presented adverse side-effects until now (Fernández-L et al. 2007). However, there is a contraindication for TA in those patients prone to suffer thrombosis. In patients with high levels of coagulation factors, therapies that avoid bleeding may lead to deep venous thromboembolism, therefore alternative therapeutic sources to counteract HHT epistaxis are needed. Hormonal therapy, using estradiol/norethindrone for epistaxis and gastrointestinal management of HHT, has shown a variable degree of efficacy depending on the patient. A case based report with long-term cessation of epistaxis using tamoxifen in a postmenopausal woman was described (Zacharski et al. 2001). Based on these reports, the efficacy of raloxifene, another estrogen receptor modulator (SERM) as tamoxifen, was assessed in 19 postmenopausal HHT women (Albiñana et al. 2010). Raloxifene, a second generation SERM, exhibits an improved clinical profile versus that of tamoxifen and is currently used for the treatment and prevention of post-menopausal osteoporosis. These HHT women patients diagnosed with osteoporosis with ages ranging from 47 to 74 years, had no contraindication for the hormonal therapy, and were good candidates for a hormonal substitutive therapy. After the treatment, all of them showed an improvement of the HHT symptoms concerning epistaxis. The effects on epistaxis were evaluated after 6 months based on the Sadick-designed scale. This scale evaluates the amount and frequency of nose bleeds. In the nineteen patients treated with raloxifene, a decrease in the frequency and the quantity of epistaxis was observed in all patients with at least one grade in the Sadick scale: average of 2.36 versus 1.31 after treatment and 2.26 versus 1.42 after treatment, respectively (Albiñana et al. 2010).

Using in vitro cellular experiments, we have also addressed the possible molecular mechanism of action of TA and raloxifene. Both, TA and raloxifene upregulate endoglin and ALK1 protein and mRNA levels as well as their gene promoter activities, suggesting a positive effect on gene transcription. In this regard, we were able to show by chromatin immunoprecipitation experiments that estrogen receptors are involved in the raloxifene-induced transcription. In addition, tube formation in matrigel and wound healing experiments indicate that TA and 
Table 1. Different types of pharmacological drugs used to treat bleeding in HHT Centers.

\begin{tabular}{ll}
\hline Therapeutic strategy & Observations \\
\hline Antifibrinolytics & $\begin{array}{l}\varepsilon \text {-aminocaproic acid (AC), tranexamic acid (TA). } \\
\text { Not appropriate when patients have pro-thrombotic clinical history, or high } \\
\text { level of coagulation factors V and VIII. }\end{array}$ \\
& $\begin{array}{l}\text { Estrogen/progesterone, ethinyl, estradiol/norethindrone, danazol, } \\
\text { phyto-estrogens, SERM (Selective Estrogen Receptor Modulator) like } \\
\text { tamoxifene and raloxifene. }\end{array}$ \\
Hormonal estrogen therapy & $\begin{array}{l}\text { Thalidomide, bevacizumab (avastin). } \\
\text { Currently used in trials. Only for severe cases. }\end{array}$ \\
Anti-angiogenic drugs (anti-VEGF) & $\begin{array}{l}\text { Sirolimus, tacrolimus, IFN } \gamma . \\
\text { Only case reports available on kidney/liver HHT transplanted patients. Not } \\
\text { enough information up to the moment. }\end{array}$ \\
Immunosuppressant agents & N-acetylcysteine \\
compounds &
\end{tabular}

raloxifene promote functions dependent on the TGF- $\beta$ /ALK1/endoglin pathway. The mechanism by which these drugs are able to stimulate this TGF- $\beta$ pathway remains to be elucidated (Fernández-L et al. 2007, Albiñana et al. 2010). In summary, these experiments support the hypothesis that TA and raloxifene are counteracting, at least partially, endoglin or ALK1 haploinsufficiency in HHT patients.

\section{REFERENCES}

Abdalla SA, Letarte M: Hereditary haemorrhagic telangiectasia: current views on genetics and mechanisms of disease. J Med Genet 43:97-110, 2006.

Albiñana V, Bernabeu-Herrero ME, Zarrabeitia R, Bernabéu C, Botella LM: Estrogen therapy for hereditary haemorrhagic telangiectasia (HHT): Effects of raloxifene, on Endoglin and ALK1 expression in endothelial cells. Thromb Haemost 103:525-534, 2010.

Bellon T, Corbi A, Lastres P, Cales C, Cebrián M, Vera S, Cheifetz S, Massague J, Letarte M, Bernabéu C: Identification and expression of two forms of the human transforming growth factor-beta-binding protein endoglin with distinct cytoplasmic regions. Eur J Immunol 23:2340-2345, 1993.

Bernabéu C, Conley BA, Vary CP: Novel biochemical pathways of endoglin in vascular cell physiology. J Cell Biochem 102:1375-1388, 2007.

Bernabéu C, López-Novoa JM, Quintanilla M: An emerging role of TGF- $\beta$ co-receptors in cancer. Biochem Biophys Acta 1792:954-973, 2009.

Blanco FJ, Santibanez JF, Guerrero-Esteo M, Langa $\mathrm{C}$, Vary CP, Bernabéu C: Interaction and functional interplay between endoglin and ALK-1, two components of the endothelial transforming growth factor-beta receptor complex. J Cell Physiol 204:574-584, 2005.

Blanco FJ, Grande MT, Langa C, Oujo B, Velasco S, Rodríguez-Barbero A, Pérez-Gómez E, Quintanilla M, López-Novoa JM, Bernabéu C: $\mathrm{S}$-endoglin expression is induced in senescent endothelial cells and contributes to vascular pathology. Circ Res 103:1383-1392, 2008.

Botella LM, Sánchez-Elsner T, Rius C, Corbí A, Bernabéu C: Identification of a critical Sp1 site within the endoglin promoter and its involvement in the transforming growth factor-beta stimulation. J Biol Chem 276:34486-3494, 2001.

Botella LM, Sánchez-Elsner T, Sanz-Rodriguez F, Kojima S, Shimada J, Guerrero-Esteo M, Cooreman MP, Ratziu V, Langa C, Vary CP, Ramirez JR, Friedman S et al.: Transcriptional activation of endoglin and transforming growth factor-beta signaling components by cooperative interaction between Sp1 and KLF6: their potential role in the response to vascular injury. Blood 100:4001-4010, 2002.

David L, Feige JJ, Bailly S: Emerging role of bone morphogenetic proteins in angiogenesis. Cytokine Growth Factor Rev 20:203-212, 2009. 
Faughnan ME, Palda VA, Garcia-Tsao G, Geisthoff UW, McDonald J, Proctor DD, Spears J, Brown DH, Buscarini E, Chesnutt MS, Cottin V, Ganguly A et al.: International Guidelines for the Diagnosis and Management of Hereditary Hemorrhagic Telangiectasia. J Med Genet published online June 23, 2009 doi:10.1136/jmg.2009.069013

Fernández-L A, Sanz-Rodriguez F, Zarrabeitia R, Pérez-Molino A, Hebbel RP, Nguyen J, Bernabéu C, Botella LM: Blood outgrowth endothelial cells from hereditary haemorrhagic telangiectasia patients reveal abnormalities compatible with vascular lesions. Cardiovasc Res 68:235-248, 2005.

Fernández-L A, Garrido-Martin EM, Sanz-Rodriguez F, Ramirez JR, Morales-Angulo C, Zarrabeitia R, Pérez-Molino A, Bernabéu C, Botella LM: Therapeutic action of tranexamic acid in hereditary haemorrhagic telangiectasia (HHT): regulation of ALK-1/endoglin pathway in endothelial cells. Thromb Haemost 97:254-262, 2007.

Fernández-Ruiz E, St-Jacques S, Bellón T, Letarte M, Bernabéu C: Assignment of the human endoglin gene (END) to 9q34>qter. Cytogenet Cell Genet 64:204-207, 1993.

Fonsatti E, Nicolay HJ, Altomonte M, Covre A, Maio $\mathrm{M}$ : Targeting cancer vasculature via endoglin/cd105: a novel antibody-based diagnostic and therapeutic strategy in solid tumors. Cardiovasc Res 86:12-19, 2010.

Fontalba A, Fernández-L A, García-Alegria E, Albiñana V, Garrido-Martin EM, Blanco FJ, Zarrabeitia R, Pérez-Molino A, Bernabeu-Herrero ME, Ojeda ML, Fernandez-Luna JL, Bernabéu C et al.: Mutation study of Spanish patients with hereditary hemorrhagic telangiectasia. BMC Med Genet 9:75, 2008.

Gallione C, Aylsworth AS, Beis J, Berk T, Bernhardt B, Clark RD, Clericuzio C, Danesino C, Drautz J, Fahl J, Fan Z, Faughnan ME et al.: Overlapping spectra of SMAD4 mutations in juvenile polyposis (JP) and JP-HHT syndrome. Am J Med Genet A 152A:333-339, 2010.

Gordon KJ, Blobe GC: Role of transforming growth factor-beta superfamily signaling pathways in human disease. Biochim Biophys Acta 1782:197-228, 2008.

Gougos A, Letarte M: Primary structure of endoglin, an RGD-containing glycoprotein of human endothelial cells. J Biol Chem 265:8361-8364, 1990.

Goumans MJ, Liu Z, ten Dijke P: TGF-beta signaling in vascular biology and dysfunction. Cell Res 19:116-127, 2009.
Govani FS, Shovlin CL: Hereditary haemorrhagic telangiectasia: a clinical and scientific review. Eur J Hum Genet 17:860-871, 2009.

Guerrero-Esteo M, Sánchez-Elsner T, Letamendia A, Bernabéu C: Extracellular and cytoplasmic domains of endoglin interact with the transforming growth factor-beta receptors I and II. J Biol Chem 277:29197-29209, 2002.

Henry-Berger J, Mouzat K, Baron S, Bernabéu C, Marceau G, Saru JP, Sapin V, Lobaccaro JM, Caira F: Endoglin (CD105) expression is regulated by the liver $\mathrm{X}$ receptor alpha (NR1H3) in human trophoblast cell line JAR. Biol Reprod 78:968-975, 2008.

Jerkic M, Rivas-Elena JV, Santibanez JF, Prieto M, Rodríguez-Barbero A, Perez-Barriocanal F, Pericacho M, Arévalo M, Vary CP, Letarte M, Bernabéu C, López-Novoa JM: Endoglin regulates cyclooxygenase- 2 expression and activity. Circ Res 99:248-256, 2006.

Johnson DW, Berg JN, Baldwin MA, Gallione CJ, Marondel I, Yoon SJ, Stenzel TT, Speer M, Pericak-Vance MA, Diamond A, Guttmacher AE, Jackson CE et al.: Mutations in the activin receptor-like kinase 1 gene in hereditary haemorrhagic telangiectasia type 2. Nat Genet 13:189-195, 1996.

Jovine L, Darie CC, Litscher ES, Wassarman PM: Zona pellucida domain proteins. Annu Rev Biochem 74:83-114, 2005.

Lebrin F, Mummery CL: Endoglin-mediated vascular remodeling: mechanisms underlying hereditary haemorrhagic telangiectasia. Trends Cardiovasc Med 18:25-32, 2008

Li X, Yonenaga Y, Seki T: Shortened ALK1 regulatory fragment maintains a specific activity in arteries feeding ischemic tissues. Gene Ther 16:1034-1041, 2009.

Llorca O, Trujillo A, Blanco FJ, Bernabéu C: Structural model of human endoglin, a transmembrane receptor responsible for hereditary hemorrhagic telangiectasia. J Mol Biol 365:694-705, 2007.

Mannucci PM: Hemostatic drugs. N Engl J Med 339:245-253, 1998.

McAllister KA, Grogg KM, Johnson DW, Gallione CJ, Baldwin MA, Jackson CE, Helmbold EA, Markel DS, McKinnon WC, Murrell J, McCormick MK, Pericak-Vance MA et al.: Endoglin, a TGF- $\beta$ binding protein of endothelial cells, is the gene for hereditary haemorrhagic telangiectasia type 1. Nat Genet 8:345-351, 1994.

Pérez-Gómez E, Eleno N, López-Novoa JM, Ramirez JR, Velasco B, Letarte M, Bernabéu C, Quintanilla M: Characterization of murine 
S-endoglin isoform and its effects on tumor development. Oncogene 24:4450-4461, 2005.

Pérez-Gómez E, Villa-Morales M, Santos J, Fernández-Piqueras J, Gamallo $\mathrm{C}$, Dotor J, Bernabéu C, Quintanilla M: A role for endoglin as a suppressor of malignancy during mouse skin carcinogenesis. Cancer Res 67:10268-10277, 2007.

Pimanda JE, Chan WY, Wilson NK, Smith AM, Kinston S, Knezevic K, Janes ME, Landry JR, Kolb-Kokocinski A, Frampton J, Tannahill D, Ottersbach $\mathrm{K}$ et al.: Endoglin expression in blood and endothelium is differentially regulated by modular assembly of the Ets/Gata hemangioblast code. Blood 112:4512-4522, 2008.

Plauchu H, de Chadarévian JP, Bideau A, Robert JM: Age-related clinical profile of hereditary hemorrhagic telangiectasia in an epidemiologically recruited population. Am J Med Genet 32:291-297, 1989.

Rius C, Smith JD, Almendro N, Langa C, Botella LM, Marchuk DA, Vary CP, Bernabéu C: Cloning of the promoter region of human endoglin, the target gene for hereditary hemorrhagic telangiectasia type 1. Blood 92:4677-4690, 1998.

Sabba C, Gallitelli M, Palasciano G: Efficacy of unusually high doses of tranexamic acid for the treatment of epistaxis in hereditary hemorrhagic telangiectasia. N Engl J Med 345:926, 2001.

Sánchez-Elsner T, Botella LM, Velasco B, Langa C, Bernabéu C: Endoglin expression is regulated by transcriptional cooperation between the hypoxia and transforming growth factor- $\beta$ pathways. J Biol Chem 277:43799-43808, 2002.

Santibanez JF, Letamendia A, Perez-Barriocanal F, Silvestri C, Saura M, Vary CP, López-Novoa JM,
Attisano L, Bernabéu C: Endoglin increases eNOS expression by modulating Smad2 protein levels and Smad2-dependent TGF-beta signaling. J Cell Physiol 210:456-468, 2007.

Santibanez JF, Blanco FJ, Garrido-Martin EM, Sanz-Rodriguez F, del Pozo MA, Bernabéu C: Caveolin-1 interacts and cooperates with the transforming growth factor-beta type I receptor ALK1 in endothelial caveolae. Cardiovasc Res 77:791-799, 2008.

Sanz-Rodriguez F, Guerrero-Esteo M, Botella LM, Banville D, Vary CP, Bernabéu C: Endoglin regulates cytoskeletal organization through binding to ZRP-1, a member of the Lim family of proteins. J Biol Chem 279:32858-32868, 2004.

Shovlin CL, Guttmacher AE, Buscarini E, Faughnan ME, Hyland RH, Westermann CJ, Kjeldsen AD, Plauchu H: Diagnostic criteria for hereditary hemorrhagic telangiectasia (Rendu-Osler-Weber syndrome). Am J Med Genet 91:66-67, 2000.

Velasco S, Alvarez-Muñoz P, Pericacho M, Dijke PT, Bernabéu C, López-Novoa JM, Rodríguez-Barbero A: L- and S-endoglin differentially modulate TGFbeta1 signaling mediated by ALK1 and ALK5 in L6E9 myoblasts. J Cell Sci 121:913-919, 2008.

Wong VC, Chan PL, Bernabéu C, Law S, Wang LD, Li JL, Tsao SW, Srivastava G, Lung ML: Identification of an invasion and tumor-suppressing gene, Endoglin (ENG), silenced by both epigenetic inactivation and allelic loss in esophageal squamous cell carcinoma. Int J Cancer 123:2816-2823, 2008.

Zacharski LR, Dunbar SD, Newsom WA, Jr.: Hemostatic effects of tamoxifen in HHT. Thromb Haemost 85:371-372, 2001. 